\title{
Human-Human Hybridoma Autoantibodies with Both Anti-DNA and Rheumatoid Factor Activities
}

\author{
Joyce Rauch, Hyman Tannenbaum, Karin Straaton, Hélène Massicotte, and Joanne Wild
}

Rheumatic Disease Unit, The Montreal General Hospital Research Institute, McGill University, Montreal, Quebec, H3G 1 A4 Canada

\begin{abstract}
Human hybridomas have been produced by fusing peripheral blood lymphocytes from patients with rheumatoid arthritis (RA) and systemic lupus erythematosus (SLE) with the GM 4672 human cell line. 262 hybridoma clones from the fusions of four RA and five SLE patients were screened for binding to denatured DNA (dDNA), native DNA, and the Fc fragment of human IgG (HIgG). Of the 17 hybridoma antibodies (nine RA, eight SLE) selected for strong binding to denatured DNA, Fc, or both, five reacted with dDNA only, one with Fc only, and eight with both dDNA and Fc. Hybridoma supernatants exhibiting dual reactivity were absorbed over HIgG and bovine serum albumin (BSA)Sepharose immunoabsorbent columns. The reactivities to both DNA and HIgG were completely removed by the HIgG column but unaffected by passage over the BSA column, and both DNA binding and rheumatoid factor activities were recovered in the acid eluates from the Sepharose-IgG column. The binding of dual reactive hybridoma autoantibodies to the Fc fragment of HIgG was specifically competed by dDNA and HIgG, providing additional evidence that one antibody may be capable of reacting both as a rheumatoid factor and as an anti-DNA antibody.
\end{abstract}

\section{Introduction}

Rheumatoid factors (RF) ${ }^{1}$ have classically been defined as antiIgG immunoglobulins that react with autologous and heterologous IgG. They are detected in $\sim 70 \%$ of patients with rheumatoid arthritis (RA), $30 \%$ of patients with systemic lupus erythematosus (SLE), as well as in patients with other connective tissue diseases (1). In addition, RF can be found in patients with chronic inflammatory diseases, such as leprosy, tuberculosis, syphilis, subacute endocarditis, and salmonellosis, and in other conditions associated with hypergammaglobulinemia or circulating immune complexes (1). The origin and function of antiimmunoglobulin antibodies (RF) in each of these diseases is

Part of this work was presented as a poster session at the American Association of Immunologists Meeting, St. Louis, MO, 1984 (1984. Fed. Proc. 43:1832).

Address reprint requests to Dr. Rauch.

Received for publication 16 July 1984 and in revised form 29 August 1985.

1. Abbreviations used in this paper: dDNA, denatured DNA; HIgG, human IgG; nDNA, native DNA; PBL, peripheral blood lymphocytes; PBS, phosphate-buffered saline, pH 7.3; PTT, partial thromboplastin time; RA, rheumatoid arthritis; RF, rheumatoid factor(s); RIA, radioimmunoassay(s); SLE, systemic lupus erythematosus.

J. Clin. Invest.

(C) The American Society for Clinical Investigation, Inc.

0021-9738/86/01/0106/07\$ \$1.00

Volume 77, January 1986, 106-112 unknown. However, studies on monoclonal and polyclonal RF isolated from serum have shown that $R F$ can react with a variety of substances other than IgG, including nitrophenyl groups and denatured DNA (dDNA) (2), nucleosomes $(3,4)$, DNA-nucleoprotein complexes (5), histones (6-8), nonhistone nuclear proteins (9), and bromelin-treated erythrocytes (10). The basis of these cross-reactivities is difficult to explain, since these antigens do not appear to exhibit significant structural homology with IgG. Human-human hybridoma autoantibodies derived from patients with RA and SLE provide the means to isolate and analyze individual monoclonal RF and to determine their crossreactivities with other antigens. The nature of the cross-reactions of these hybridoma autoantibodies with different antigens may provide important insight into the properties of the antigen binding site and the mechanisms responsible for the production and pathogenesis of these autoantibodies.

Our observations on 17 hybridoma autoantibodies derived from RA and SLE patients indicate that a single autoantibody can function both as an RF and an anti-DNA antibody. We found that many hybridoma antibodies, which were originally selected for their capacity to bind to DNA, also had reactivity to the Fc fragment of IgG. The dual reactivities were demonstrated to be due to a single antibody by $(a)$ direct binding radioimmunoassays (RIA), (b) affinity chromatography, (c) competitive RIA analysis on Fc coated tubes, and $(d)$ isoelectric focusing.

\section{Methods}

Fusion. $50 \mathrm{ml}$ of venous blood was obtained from each of five patients who satisfied the revised American Rheumatism Association criteria for the classification of SLE (11) and from four patients with classical RA (12). The peripheral blood lymphocytes (PBL) were isolated on a FicollHypaque gradient and immediately fused with the GM 4672 human lymphoblastoid cell line, which was obtained from the Cell Repository Institute of Medical Research, Camden, $\mathrm{NJ}$, at cell ratios of $5: 1$ and 1:1 using 44.4\% polyethylene glycol 1540 (J.T. Baker Chemical Co., Phillipsburg, NJ) (13).

Selection of hybridomas producing autoantibodies to dDNA, native $D N A(n D N A)$, and $F c$. All hybridoma supernatants were tested for the production of antibodies to dDNA, nDNA, and Fc in solid-phase RIA. Hybridomas that secreted antibodies to any or all three antigens were selected for propagation and cloned by limiting dilution at 1 cell/well.

Solid-phase RIA for antibody binding to $d D N A$ and $n D N A$. Solidphase RIA were used to detect antibodies to dDNA and nDNA. IDNA was obtained by boiling a solution of $0.5 \mathrm{mg} / \mathrm{ml}$ of calf thymus DNA (Millipore Corp., Freehold, NJ) dissolved in $0.015 \mathrm{M}$ saline sodium citrate

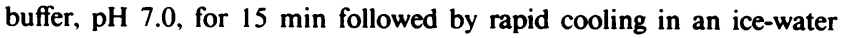
bath. $\mathrm{nDNA}$ was prepared by $\mathrm{S} 1$ nuclease digestion of calf thymus DNA and subsequent purification on a Sephacryl S-200 column. Polystyrene tubes (Stockwell Scientific, Monterey Park, CA) were coated overnight with $0.2 \mathrm{ml}$ of a $2.5-\mu \mathrm{g} / \mathrm{ml}$ solution of dDNA or nDNA. Control tubes were coated with $2.5 \mu \mathrm{g} / \mathrm{ml}$ of bovine serum albumin (BSA) (Sigma Chemical Co., St. Louis, MO) to determine the nonspecific binding of the hybridoma antibodies to an irrelevant antigen. The tubes were washed 
once with $0.1 \mathrm{M}$ potassium phosphate buffer $\left(\mathrm{KPO}_{4}\right), \mathrm{pH} 7.0$, containing $0.1 \%$ BSA and $0.01 \%$ Tween 20 (RIA buffer), and incubated in the same buffer for $45 \mathrm{~min}$ at $37^{\circ} \mathrm{C} .75 \mu \mathrm{l}$ of hybridoma culture fluid was added to duplicate tubes and incubated for $1 \mathrm{~h}$ at $37^{\circ} \mathrm{C}$. The negative controls included $\mathrm{KPO}_{4}$ buffer, GM $4672 \mathrm{IgG}$, and a non-DNA-binding, nonIgG-binding IgM hybridoma antibody (1500). The amount of immunoglobulin present in each culture supernatant varied from 0.6 to 40 $\mu \mathrm{g} / \mathrm{ml}$. Each culture supernatant was adjusted to an IgM concentration of $2 \mu \mathrm{g} / \mathrm{ml}$ immediately before testing in the RIA. After aspiration of the sample and three washes with RIA buffer, $100 \mu$ l of ${ }^{125}$ I-radiolabeled affinity-purified sheep antibodies to human IgM and IgG was added and the tubes were incubated overnight at $4^{\circ} \mathrm{C}$. The tubes were then washed three times with RIA buffer and were counted for bound ${ }^{125}$ I-radioactivity in a gamma counter (Beckman Instruments Inc., Fullerton, CA). Antibodies were considered to be positive for binding to a particular antigen if the cpm bound to the antigen exceeded $3 \mathrm{SD}$ above the mean of the negative controls.

Preparation of immunoglobulins. (1) Human IgG (hIgG): IgG was purified from human Cohn fraction II (Sigma Chemical Co.) by chromatography on DEAE cellulose in $0.01 \mathrm{M}$ sodium phosphate buffer, $\mathrm{pH}$ 8.0 (14). (2) Rabbit anti-human IgM: Rabbit anti-human IgM (mu specific) (Cappel Laboratories, Cochranville, PA) was negatively absorbed on a column of DEAE-purified human IgG coupled to $\mathrm{CNBr}$-Sepharose (Pharmacia Fine Chemicals, Uppsala, Sweden) and the rabbit immunoglobulin was then positively absorbed on a protein A-Sepharose column (Pharmacia Fine Chemicals). The purified rabbit anti-human IgM was radioiodinated with ${ }^{125} \mathrm{I}$ using the chloramine $\mathrm{T}$ method (15).

Purification of Fab and Fc fragments of Human IgG. $150 \mathrm{mg}$ of DEAE-purified human IgG in $0.1 \mathrm{M}$ potassium phosphate buffer, $\mathrm{pH}$ 7.0 , was digested with $1.5 \mathrm{mg}$ crystallized papain (Worthington Biochemical Corp., Freehold, NJ) for $16 \mathrm{~h}$ at $37^{\circ} \mathrm{C}(16)$. The digested IgG was then fractionated on a $2.5 \times 20$-cm CM-Sepharose column (Pharmacia Fine Chemicals) equilibrated in $0.1 \mathrm{M}$ sodium phosphate buffer, pH 7.6, using a stepwise gradient elution of $0-0.4 \mathrm{M} \mathrm{NaCl}$ (16). The fraction containing Fab and Fc fragments was applied to a $2.5 \times 24-\mathrm{cm}$ DEAE cellulose (Whatman Ltd., Maidstone, Kent, England) column in $0.1 \mathrm{M}$ sodium phosphate buffer, $\mathrm{pH} 8.0$, and eluted with a stepwise gradient of $0-0.3 \mathrm{M} \mathrm{NaCl}$. The material that eluted with $0.1 \mathrm{M}$ sodium phosphate buffer, $\mathrm{pH} 8.0$, was pooled, concentrated, and applied to a 5$\mathrm{ml}$ protein A-Sepharose column (Pharmacia Fine Chemicals). The protein A-Sepharose-bound material was eluted with $0.1 \mathrm{M}$ glycine- $\mathrm{HCl}, \mathrm{pH}$ 2.3 , and dialyzed against two changes of $\mathrm{pH} 7.3$ phosphate-buffered saline, (PBS), at $4^{\circ} \mathrm{C}$. The $\mathrm{Fc}$-containing fraction was finally isolated from a rabbit anti-human IgG (Fc-specific)-Sepharose immunoabsorbent column by elution with $0.1 \mathrm{M}$ glycine- $\mathrm{HCl}, \mathrm{pH} 2.3$ and dialysis against PBS. Purified Fab fragments were isolated from the DEAE cellulose fraction above by negative absorption on the rabbit anti-human IgG (Fcspecific)-Sepharose column. Isolated $\mathrm{Fab}$ and $\mathrm{Fc}$ fragment preparations were checked for purity in Ouchterlony immunodiffusion plates against rabbit anti-human-Fc and rabbit anti-human-Fab specific antisera (Cappel Laboratories).

Solid-phase RIA for IgM RF. Hybridoma supernatants were screened for RF activity using a solid-phase RIA (17). Polystyrene tubes $(12 \times 75$ $\mathrm{mm}$ ) were coated overnight at $4^{\circ} \mathrm{C}$ with $0.2 \mathrm{ml}$ of a $2.5-\mu \mathrm{g} / \mathrm{ml}$ solution of either Fc or Fab in $0.025 \mathrm{M}$ Tris-buffered saline, $\mathrm{pH}$ 7.4. Tubes coated with $2.5 \mu \mathrm{g} / \mathrm{ml}$ BSA in Tris-buffered saline served as controls for nonspecific hybridoma antibody binding. The coating solution was aspirated and the tubes were washed twice with $0.01 \mathrm{M}$ potassium phosphate $\left(\mathrm{KPO}_{4}\right)$ buffer, $\mathrm{pH} 7.0$, containing $0.1 \%$ BSA and $0.01 \%$ Tween 20 (RIA buffer). The second RIA buffer wash was left in the tubes for $1 \mathrm{~h}$ at room temperature to saturate any unoccupied sites on the polystyrene tubes. After an additional wash with RIA buffer, $75 \mu \mathrm{l}$ of sample was added to duplicate tubes and incubated for $24 \mathrm{~h}$ at $4^{\circ} \mathrm{C}$. All hybridoma supernatants and a non-Fc, non-Fab binding control hybridoma antibody (1500) were tested at $2 \mu \mathrm{g} \mathrm{IgM} / \mathrm{ml}$. A monoclonal RF isolated from serum, kindly provided by Dr. Jack Karsh (Ottawa General Hospital), was diluted in assay buffer to $2 \mu \mathrm{g} / \mathrm{ml}$. The tubes were then washed three times with buffer, and $100 \mu \mathrm{l}$ of ${ }^{125}$ I-labeled rabbit anti-human IgM (100,000 cpm/ tube) was added and incubated overnight at $4^{\circ} \mathrm{C}$. The tubes were washed three times with buffer and then counted for $1 \mathrm{~min}$ in a gamma counter (Beckman Instruments Inc.).

Competition of binding of hybridoma RF to Fc-coated tubes by HIgG, $d D N A$, and $B S A .100 \mu \mathrm{l}$ of a dilution of hybridoma culture fluid, which gave $50-60 \%$ of maximum binding to Fc-coated tubes, was incubated with $100 \mu$ l of dilutions of DEAE-purified HIgG, dDNA, or BSA (Sigma Chemical Co.) in $12 \times 75-\mathrm{mm}$ glass tubes overnight at $4^{\circ} \mathrm{C} .75 \mu \mathrm{l}$ of the mixture was then added, in duplicate, to Fc-coated tubes, and incubated overnight at $4^{\circ} \mathrm{C}$. The tubes were then washed three times with buffer, and $100 \mu$ of ${ }^{125} \mathrm{I}$-radiolabeled rabbit anti-human IgM (100,000 cpm/ tube) was added and incubated overnight at $4^{\circ} \mathrm{C}$. The tubes were again washed three times with buffer and counted for bound ${ }^{125}$ I-radioactivity in a gamma counter (Beckman Instruments Inc.). The results, expressed as percentage binding, were calculated from the ratio of $\mathrm{cpm}$ bound by the hybridoma antibody in the presence of antigen competitor (hIgG, dDNA, or BSA) over the cpm bound in the absence of competitor (buffer only).

Absorption of hybridoma anti-DNA antibodies on Sepharose-HIgG and Sepharose-BSA immunoabsorbents. Sepharose-HIgG and SepharoseBSA immunoabsorbents were prepared by coupling DEAE-purified human IgG and purified BSA, respectively, to CNBr-Sepharose (Pharmacia Fine Chemicals) at a concentration of $5 \mathrm{mg}$ protein $/ \mathrm{ml}$ Sepharose.

Absorptions were performed in tubes as opposed to columns in order to achieve minimal dilution of the applied sample, thus eliminating the necessity of concentrating effluents and eluates back to the original sample volume. For the tube absorptions, equal aliquots of Sepharose-HIgG and Sepharose-BSA immunoabsorbents in PBS were centrifuged in glass test tubes and the excess PBS was removed. $2 \mathrm{ml}$ of each hybridoma culture fluid was added to one tube that contained $2 \mathrm{ml}$ of packed SepharoseHIgG immunoabsorbent and to a second tube that contained $2 \mathrm{ml}$ of packed Sepharose-BSA immunoabsorbent. The antibody-containing culture fluids were incubated with the immunoabsorbents on an endover-end rotator for $16-18 \mathrm{~h}$ at $4^{\circ} \mathrm{C}$. The immunosorbent gels were then centrifuged and the supernatants (effluents) carefully removed and filtered through a 5- $\mu \mathrm{m}$ Millipore membrane to remove fine gel particles. The gels were then washed with $3 \mathrm{ml}$ of PBS and were packed in small columns for further washing with $30 \mathrm{ml}$ of PBS and $30 \mathrm{ml}$ of $0.5 \mathrm{M} \mathrm{NaCl}$. The material that was bound to the immunoabsorbent was then eluted with $2 \mathrm{ml} 0.1 \mathrm{M}$ sodium acetate buffer, $\mathrm{pH} 4.0$, containing $0.5 \mathrm{M} \mathrm{NaCl}$, as described previously (18). The eluates were immediately neutralized with one drop of $1 \mathrm{M}$ Tris buffer and $75 \mu \mathrm{l}$ of $7.5 \% \mathrm{BSA}$ (Gibco, Grand Island, NY) was added to stabilize the RF and anti-DNA activities (little or no activity was recovered without this addition of BSA, since the extremely small amounts of pure antibody were either unstable or lost in dialysis). The eluates were then dialyzed overnight at $4^{\circ} \mathrm{C}$ against two changes of $0.1 \mathrm{M} \mathrm{KPO}_{4}$ buffer, $\mathrm{pH}$ 7.0. Hybridoma culture fluids and immunoabsorbent effluents and eluates were then assayed on IDNA and Fc-coated tubes to assess anti-DNA antibody and RF activities.

As a control for nonspecific binding of antibody activity to the Sepharose-HIgG and Sepharose-BSA columns, a hybridoma supernatant (824) with lupus anticoagulant activity was passed over each immunoabsorbent column and the residual lupus anticoagulant activity in the effluent was assayed. The hybridoma supernatants and immunoabsorbent effluents were tested for their lupus anticoagulant activity using a modified activated partial thromboplastin time (PTT) assay (19).

Isoelectric focusing of hybridoma autoantibodies. Purified hybridoma antibodies were labeled by reduction with dithiothreitol and alkylation with ${ }^{14} \mathrm{C}$-iodoacetamide (Amersham Corp., Arlington Heights, IL) and heavy and light chains were separated by urea-formate gel electrophoresis according to the method of Gibson (20). Isoelectric focusing of the ureaformate gel strip containing hybridoma light chains was performed as previously described (21). The gels were fixed, stained, treated with Enhance (New England Nuclear, Boston, MA), and autoradiographed by exposure to Kodak DEF-2-X-ray film (Eastman Kodak Co., Rochester, NY) for several days to several weeks. 


\section{Results}

Production of hybridoma anti-DNA and RF antibodies from patients with SLE and RA. The fusion of PBL from four RA patients and five SLE patients with the GM 4672 lymphoblastoid line produced a total of 262 hybridoma clones. The four RA fusions resulted in 167 clones, of which two produced anti-DNA only, one produced RF only, and six produced both anti-DNA and RF. Fusions of PBL from five SLE patients produced 95 clones, of which three secreted anti-DNA antibody only, none produced RF only, and five produced both anti-DNA and RF. The frequency of clones producing both anti-DNA and RF was $6 / 167$ (4\%) for RA and 5/95 (5\%) for SLE.

Binding of hybridoma antibodies to $D D N A$ and $n D N A$. The results of the direct binding to dDNA, nDNA, and BSA (nonspecific antigen) by nine RA-derived hybridoma antibodies and eight SLE-derived hybridoma antibodies are shown in Table I. An antibody was considered to be positive for binding when the mean of the duplicate binding assay tubes exceeded the mean

Table I. Direct Binding of Human Hybridoma Antibodies from $R A$ and SLE Patients to dDNA, nDNA, and BSA-coated Tubes

\begin{tabular}{|c|c|c|c|}
\hline \multirow[b]{2}{*}{ Clone } & \multicolumn{3}{|c|}{$\begin{array}{l}\text { Binding ( } \mathrm{cpm} \text { ) of hybridoma antibody* to } \\
\text { tubes coated with: }\end{array}$} \\
\hline & dDNA & nDNA & BSA \\
\hline \multicolumn{4}{|l|}{ RA } \\
\hline 1700 & 1,699 & 705 & 529 \\
\hline 1851 & 10,531 & 650 & 715 \\
\hline 1844 & 21,678 & 817 & 465 \\
\hline 1836 & 28,208 & 948 & 649 \\
\hline 1826 & 30,573 & 794 & 742 \\
\hline $1859^{*}$ & 32,458 & 14,159 & 751 \\
\hline 1873 & 34,675 & 1,678 & 925 \\
\hline 1872 & 39,337 & 690 & 494 \\
\hline 18141 & 503 & 865 & 251 \\
\hline \multicolumn{4}{|l|}{ SLE } \\
\hline 1900 & 2,048 & 1,077 & 810 \\
\hline 2607 & 10,441 & 977 & 668 \\
\hline 2608 & 5,919 & 912 & 630 \\
\hline 1401 & 17,939 & 794 & 890 \\
\hline 600 & 24,897 & 1,126 & 756 \\
\hline 103 & 34,755 & 1,135 & 1,007 \\
\hline 1400 & 38,493 & 16,949 & 817 \\
\hline 134 & 44,069 & 10,205 & 1,027 \\
\hline \multicolumn{4}{|l|}{ Controls } \\
\hline Buffer & 332 & 855 & 308 \\
\hline GM 4672‡ & 491 & 918 & 487 \\
\hline $1500 \ddagger$ & 784 & 472 & 683 \\
\hline MRF & 478 & 850 & 395 \\
\hline
\end{tabular}

* All antibodies, except antibody 1859 , but including the 1500 IgM control and MRF (monoclonal rheumatoid factor), were tested at $2 \mu \mathrm{g}$ $\mathrm{IgM} / \mathrm{ml}$. Antibody 1859 was tested at $0.6 \mu \mathrm{g} / \mathrm{ml}$.

¥ Cell supernatants of GM 4672 (IgG producing) and 1500 (IgM producing), which bind neither DNA nor cardiolipin, were used as negative controls. An antibody was considered to be positive when the cpm bound exceeded the mean +3 SD of the controls (buffer, GM 4672 , and 1500). The mean +3 SD were 1,224 for dDNA, 1,472 for nDNA, and 1,056 for BSA.
+3 SD of the negative binding controls (buffer, GM 4672, and 1500 ). The variability of the assay was $<20 \%$ based on three consecutive experiments with each of the 17 clones. By this definition, all SLE-derived antibodies and all but one RA-derived antibody were positive for dDNA binding. Two RA and two SLE antibodies showed binding to nDNA. A total of four hybridoma antibodies (two RA and two SLE) reacted with both dDNA and nDNA. Binding to BSA did not exceed negative control binding for any of the hybridoma antibodies.

Solid-phase RIA for IgM antibodies to Fc fragments. Hybridoma antibodies were tested for binding to $\mathrm{Fc}, \mathrm{Fab}$, and BSAcoated tubes (Table II). An antibody was considered to be positive for binding when the mean binding (in $\mathrm{cpm}$ ) of the duplicate assay tubes exceeded the mean plus $3 \mathrm{SD}$ of the binding of the negative controls (buffer, GM 4672, and 1500), and this was reproduced in three experiments. Binding to BSA exceeded the negative control binding for only one hybridoma antibody (134). The binding on Fc-coated tubes was equivalent to binding on Fab-coated tubes for two RA and two SLE-derived antibodies. These antibodies were not considered to have RF activity. Three

Table II. Direct Binding of Human Hybridoma Antibodies from $R A$ and SLE Patients to Fc, Fab, and BSA-coated Tubes

\begin{tabular}{|c|c|c|c|}
\hline \multirow[b]{2}{*}{ Clone } & \multicolumn{3}{|c|}{$\begin{array}{l}\text { Binding (cpm) of hybridoma antibody* to } \\
\text { tubes coated with: }\end{array}$} \\
\hline & Fc & Fab & BSA \\
\hline \multicolumn{4}{|l|}{ RA } \\
\hline 1700 & 1,448 & 719 & 355 \\
\hline 1851 & 1,016 & 1,056 & 390 \\
\hline 1844 & 989 & 712 & 279 \\
\hline 1836 & 1,589 & 667 & 368 \\
\hline 1826 & 1,125 & 1,384 & 508 \\
\hline $1859^{*}$ & 2,806 & 946 & 634 \\
\hline 1873 & 1,109 & 789 & 436 \\
\hline 1872 & 960 & 803 & 602 \\
\hline 18141 & 6,372 & 1,027 & 540 \\
\hline \multicolumn{4}{|l|}{ SLE } \\
\hline 1900 & 1,593 & 632 & 426 \\
\hline 2607 & 3,962 & 962 & 523 \\
\hline 2608 & 647 & 805 & 469 \\
\hline 1401 & 6,228 & 788 & 700 \\
\hline 600 & 1,806 & 1,827 & 698 \\
\hline 103 & 3,048 & 832 & 505 \\
\hline 1400 & 2,569 & 1,105 & 725 \\
\hline 134 & 2,189 & 2,623 & 879 \\
\hline \multicolumn{4}{|l|}{ Controls } \\
\hline Buffer & 304 & 582 & 322 \\
\hline GM 4672 & 442 & 558 & 508 \\
\hline $1500 \ddagger$ & 462 & 832 & 471 \\
\hline MRF & 13,845 & 1,441 & 912 \\
\hline
\end{tabular}

* All antibodies, except antibody 1859, but including the 1500 IgM control and MRF (monoclonal rheumatoid factor), were tested at $2 \mu \mathrm{g}$ IgM/ml. Antibody 1859 was tested at $0.6 \mu \mathrm{g} / \mathrm{ml}$.

¥ Cell supernatants of GM 4672 (IgG producing) and 1500 (IgM producing), which bind neither Fc or Fab, were used as negative controls. An antibody was considered to be positive when the cpm bound exceeded the mean +3 SD of the controls (buffer, GM 4672, and 1500). The mean + 3 SD were 912 for Fc, 1,111 for Fab, and 728 for BSA. 
RA antibodies (1844, 1872, and 1873) had Fc binding values that were weakly positive, and one SLE antibody (2608) did not bind to Fc. 59\% (10/17) of the antibodies showed specific binding to Fc with little or no binding to Fab. These results indicate that $47 \%(8 / 17)$ of the antibodies originally detected by anti-dDNA screening assays, and one RA antibody (18141) with no DNAbinding activity showed specific and high binding to Fc relative to Fab and were, therefore, classical RF.

Absorption of hybridoma anti-DNA antibodies on SepharoseHIgG and Sepharose-BSA immunoabsorbents. The results of absorption experiments performed on one RA-derived hybridoma antibody, 1836, and one SLE-derived hybridoma antibody, 1400, which both demonstrated anti-DNA and RF activities, are presented in Table III. Equal quantities of antibody were absorbed on both Sepharose-HIgG and Sepharose-BSA immunoabsorbents. For RA clone 1836, absorption on the SepharoseHIgG gel removed $100 \%$ of the RF binding activity and $91.5 \%$ of the dDNA-binding activity. Elution from the column resulted in recovery of $83.5 \%$ of the RF activity but only $10.7 \%$ of the anti-DNA activity. Similar results were obtained for SLE antibody 1400 . In this case, $59.6 \%$ of the RF activity and $91 \%$ of the DNA-binding activity was removed by the Sepharose-HIgG gel. Elution from the column resulted in complete recovery of the RF activity, while recovery of the anti-DNA activity was only $9.8 \%$. The recovery of RF activity was actually enhanced

Table III. Absorption of Hybridoma Anti-DNA Antibodies on Sepharose-HIgG and Sepharose-BSA Immunoabsorbents

\begin{tabular}{|c|c|c|c|c|}
\hline \multirow[b]{2}{*}{ Immunoabsorbent } & \multicolumn{2}{|c|}{ RF activity } & \multicolumn{2}{|c|}{ Anti-DNA activity } \\
\hline & $\mathrm{cpm}^{*}$ & Total \% & $\mathrm{cpm}^{*}$ & Total \% \\
\hline \multicolumn{5}{|l|}{ Sepharose-HIgG } \\
\hline \multicolumn{5}{|l|}{ RA clone 1836} \\
\hline Before absorption & 510 & 100 & 12,529 & 100 \\
\hline After absorption & 0 & 0 & 1,067 & 8.5 \\
\hline Eluted fraction & 426 & 83.5 & 1,338 & 10.7 \\
\hline \multicolumn{5}{|l|}{ SLE clone 1400} \\
\hline Before absorption & 1,352 & 100 & 43,387 & 100 \\
\hline After absorption & 546 & 40.4 & 3,943 & 9.0 \\
\hline Eluted fraction & 3,326 & 246 & 4,246 & 9.8 \\
\hline \multicolumn{5}{|l|}{ Sepharose-BSA } \\
\hline \multicolumn{5}{|l|}{ RA clones 1836} \\
\hline Before absorption & 510 & 100 & 12,529 & 100 \\
\hline After absorption & 442 & 86.7 & 8,556 & 68.3 \\
\hline Eluted fraction & 0 & 0 & 22 & 0.18 \\
\hline \multicolumn{5}{|l|}{ SLE clone 1400} \\
\hline Before absorption & 1,352 & 100 & 43,387 & 100 \\
\hline After absorption & 965 & 71.4 & 17,297 & 40.0 \\
\hline Eluted fraction & 241 & 17.8 & 386 & 0.9 \\
\hline
\end{tabular}

* cpm represents the net binding to tubes coated with HIgG (for RF activity) or dDNA (for anti-DNA activity) above the binding of a negative control non-HIgG, non-DNA-binding hybridoma IgM immunoglobulin (which on HIgG and dDNA, respectively, bound 456 and $332 \mathrm{cpm}$ in the 1836 experiment, and 902 and $787 \mathrm{cpm}$ in the 1400 experiment).

$\ddagger$ Absorption on Sepharose-BSA indicates dilution by the immunoabsorption step and binding to a nonspecific immunoabsorbent under identical conditions. to $246 \%$, and this might be attributable to the greater binding efficiency of the highly purified eluted RF.

Control absorptions on Sepharose-BSA immunoabsorbents were performed on both clones RA 1836 and SLE 1400. For clone $1836,86.7 \%$ of the RF activity and $68.3 \%$ of the anti-DNA binding were recovered in the effluent fraction after absorption. Recovery in the eluted fraction was negligible $(0 \%)$ for RF activity and $0.18 \%$ for anti-DNA activity. This demonstrates that the RF and anti-DNA activities were not removed by a nonspecific immunoabsorbent gel. A comparable trend in the absorption and recovery was seen with the SLE 1400 hybridoma antibody. In the latter case, although a much higher percentage $(17.8 \%)$ of the RF activity was eluted from the Sepharose-BSA column, this must be compared with a recovery of $246 \%$ from the Sepharose-HIgG column. The recovery of anti-DNA activity in the Sepharose-BSA eluate was $<1 \%(0.9 \%)$. It should be noted that these absorptions resulted in the dilution of the effluent material by approximately one-half, due to the exchange of buffer in the immunoabsorbent with the hybridoma antibody supernatant. This dilution factor was much more evident in the case of DNA-binding activity than in the case of RF activity, due to a sharper titration effect that is particularly notable for SLE clone 1400 . Although only $40 \%$ of the anti-DNA activity was detected in the effluent of the Sepharose-BSA immunoabsorbent, the DNA-binding activity eluted from the BSA-Sepharose immunoabsorbent was $<1 \%(0.9 \%)$. This is compared with $9 \%$ recovery of anti-DNA activity in the Sepharose-HIgG column effluent and $10 \%$ recovery in the eluate of that same column.

A final control experiment was performed to ensure that unrelated antibodies without DNA-binding or RF activity would not be removed by absorption on the Sepharose-HIgG or Sepharose-BSA columns. Hybridoma antibody 824 is a non-DNAbinding and non-Fc-binding antibody that has strong lupus anticoagulant activity, as detected by a modified PTT assay. This antibody was applied to the Sepharose-HIgG and SepharoseBSA immunoabsorbents in exactly the same manner as the DNA-binding autoantibodies. Table IV shows the results of PTT

Table IV. Control Absorption of Hybridoma Lupus Anticoagulant Antibody on SepharoseHIgG and Sepharose-BSA Immunosorbents

\begin{tabular}{cll}
\hline & \multicolumn{2}{l}{ Lupus anticoagulant activity } \\
\cline { 3 - 3 } Immunoabsorbent & PTT $(s)^{*}$ & Total \% \\
\hline SLE clone 824 & & \\
Sepharose-HIgG & & \\
Before absorption & 68 & 100 \\
After absorption & 68 & 100 \\
Eluted fraction & ND & - \\
Sepharose-BSA & & \\
Before absorption & 68 & 100 \\
After absorption & 68 & 100 \\
Eluted fraction & ND & - \\
\end{tabular}

\footnotetext{
* Lupus anticoagulant activity was determined using a PTT assay that measured the prolongation of in vitro clotting times of normal plasma by hybridoma antibodies. The PTT of normal plasma in these assays was $60 \mathrm{~s}$.

$\ddagger$ ND, not determined.
} 
assays on both the hybridoma antibody applied to the immunoabsorbents and the effluent fractions from the columns. In both the case of the Sepharose-HIgG and the control SepharoseBSA column, $100 \%$ of PTT activity was recovered in the effluent after the absorption experiment. As the PTT assay used was extremely sensitive, complete recovery of this antibody activity indicated that the immunoabsorbents did not remove antibodies in a nonspecific manner.

Competition of binding of hybridoma RF to Fc-coated tubes by $H I g G, d D N A$, and BSA. Fig. 1 demonstrates the cross-reactivity of the hybridoma antibodies, which are both RF and antiDNA antibodies. As seen in Fig. 1, the binding of these antibodies to Fc-coated tubes was competed by HIgG and dDNA, but not by BSA. In the case of antibody SLE 1400 (Fig. $1 \mathrm{~A}$ ), a strong RF-reactive antibody, HIgG was a better competitor than DNA by a factor of $\sim 10$. The binding of antibody RA 1859 (Fig. 1 $B$ ) to Fc tubes, on the other hand, was competed better by dDNA than by HIgG. 50\% inhibition of binding was achieved at 0.02 $\mu \mathrm{g} / \mathrm{ml}$ of dDNA and $0.14 \mu \mathrm{g} / \mathrm{ml}$ of $\mathrm{HIgG}$, while no competition was observed at $15 \mu \mathrm{g} / \mathrm{ml}$ of BSA.

Fig. 2 shows a hybridoma RF that does not react with dDNA. This was confirmed by numerous direct binding assays on dDNA-coated tubes. Note that the competition of the binding of antibody RA 18141 to Fc-coated tubes was strongly competed
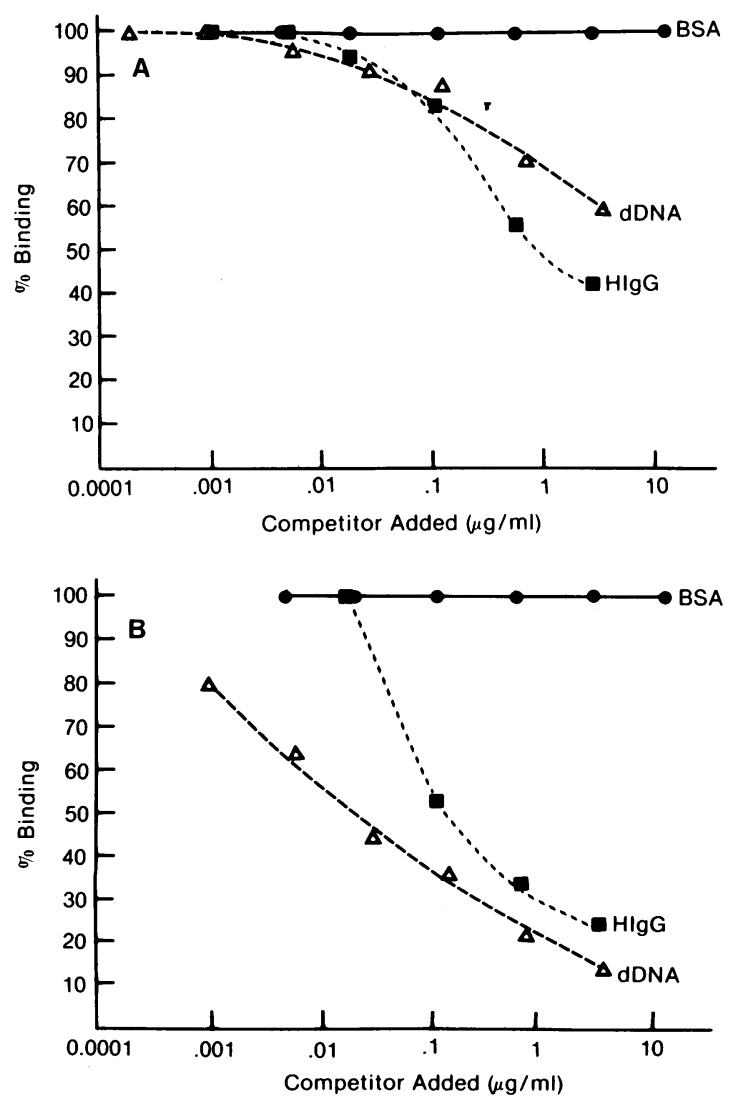

Figure 1. Competition of the binding of SLE hybridoma antibody $1400(A)$ and RA hybridoma antibody $1859(B)$ to Fc-coated tubes by dDNA, HIgG, and BSA. In direct binding assays, SLE hybridoma antibody 1400 and RA hybridoma antibody 1859 reacted strongly with Fc and dDNA. In Fig. 1, the Fc binding of these RF/anti-DNA dual reactive antibodies was competed by both $\mathrm{HIgG}$ and dDNA. The $100 \%$ binding value was determined from Fc-coated tubes incubated with the hybridoma in the absence of competitor.

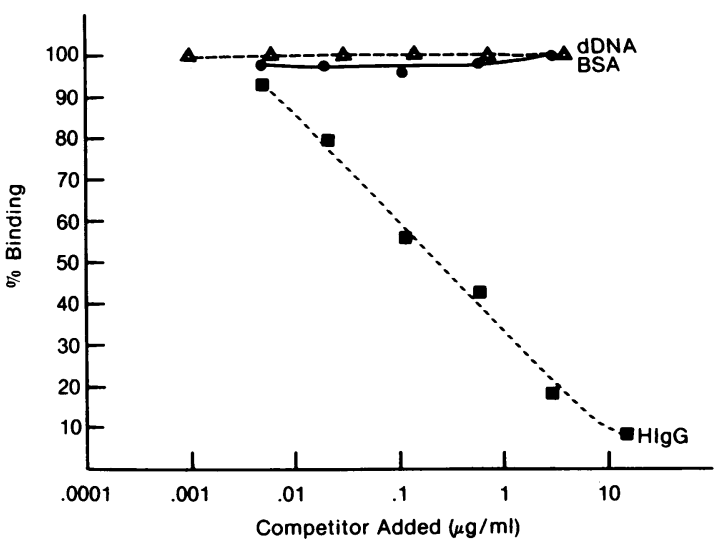

Figure 2. Competition of the binding of RA hybridoma antibody 18141 to Fc-coated tubes by dDNA, HIgG, and BSA. In direct binding assays, this hybridoma antibody reacted with $\mathrm{HIgG}$ and $\mathrm{Fc}$, but showed no reactivity to dDNA. In Fig. 2, the RF activity of RA hybridoma antibody 18141 was inhibited by HIgG but not by dDNA.

by $\mathrm{HIgG}$, with $50 \%$ inhibition attained at $0.26 \mu \mathrm{g} / \mathrm{ml} \mathrm{HIgG}$, while no competition was achieved with up to $4 \mu \mathrm{g} / \mathrm{ml}$ dDNA.

Isoelectric focusing. Fig. 3 shows a representative isoelectric focusing gel of the isolated light chains from six hybridoma antiDNA antibodies, of which four $(1836,2607,1400$, and 1401) had specific reactivity with both dDNA and Fc by direct binding RIA, competitive assays on dDNA and Fc, and immunoabsorption on Sepharose-HIgG columns. Each hybridoma antibody produced a pattern of 1-3 major bands, characteristic of the bands seen with isoelectric focusing gels of myeloma (22) and mouse monoclonal hybridoma (Gibson, D., personal communication) light chains. Interestingly, five of the six antibodies had two identical bands, suggesting a preferred light chain in these autoantibodies. The presence of 2-3 bands with heterogeneous charge properties is believed to be due to postsynthetic deamidation, or loss of labile amide groups from the immu-

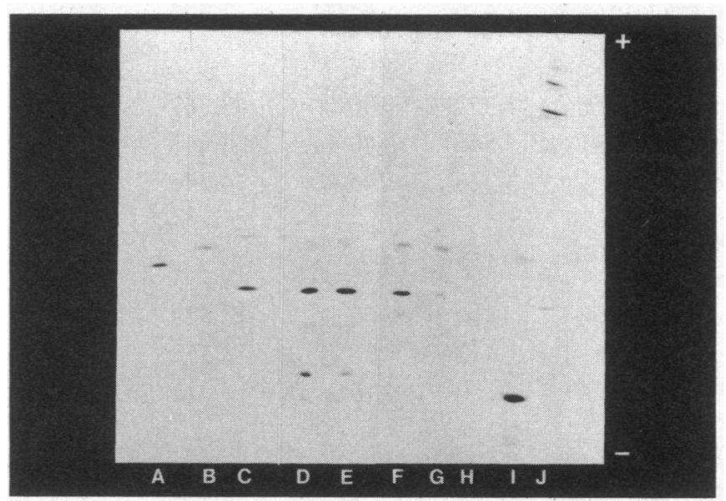

Figure 3. This is a representative isoelectric focusing gel of the light chains from the GM 4672 lymphoblastoid line, six hybridoma autoantibodies, isolated human light chain, and isolated human IgM myeloma protein (Cappel Laboratories). Sample $A$ is GM 4672 IgG; samples $B-H$ are hybridoma antibodies 1401, 1400, 134-2 (a subclone of clone 134), 134, 1400, 2607, and 1836; sample $I$ is isolated human light chain; and sample $J$ is isolated HIgM myeloma protein. Five $(1400,134-2,134,2607$, and 1836) of the six hybridoma autoantibodies showed two bands in identical positions. The double bands may be accounted for by charge differences resulting from deamidation. Another hybridoma antibody (1401) shows a single band of different mobility. 
noglobulin molecules. This can result in mobility shifts of a single- or double-band spacing (22).

Of the 17 clones listed in Table I, only 10 were examined by isoelectric focusing, and 9 were monoclonal. The one antibody (18141) that did not appear to be monoclonal was not reactive with both DNA and Fc, but reacted solely as a RF. The remaining seven clones were lost to contamination, and frozen aliquots of cells, when thawed, were no longer viable, leaving us unable to perform isoelectric focusing on the antibodies produced by these clones. Thus, all eight clones that manifested strong dual reactivity as RF and anti-DNA autoantibodies were analyzed by isoelectric focusing and all were monoclonal.

\section{Discussion}

This study demonstrates that a single human hybridoma autoantibody can have both anti-DNA and RF reactivities. Of 262 hybridomas obtained from RA and SLE patients, 17 hybridomas were found to produce antibodies that reacted with either dDNA, the Fc fragment of human IgG, or both. $6 \%(1 / 17)$ reacted with Fc only, 29\% (5/17) with dDNA only, and $65 \%$ with both Fc and dDNA. The study focuses, in particular, on the eight hybridoma antibodies with the strongest reactivities with both dDNA and Fc, and demonstrates, by direct binding, inhibition studies, immunoabsorbent experiments, and isoelectric focusing gels, that both antibody activities are due to a single hybridoma antibody.

Antibodies with both RF reactivity and high dDNA-binding activity were applied to Sepharose-HIgG and Sepharose-BSA immunoabsorbent columns. The Sepharose-HIgG immunoabsorbent removed $100 \%$ of the RF and $91.5 \%$ of the anti-DNA activities for RA hybridoma 1836 , and $60 \%$ of the RF and $91 \%$ of the anti-DNA activities of SLE hybridoma 1400. A second absorption of SLE hybridoma antibody 1400 on the SepharoseHIgG column (results not shown) removed the remaining $40 \%$ RF and $9 \%$ anti-DNA activities present after the first SepharoseIgG absorption. In both the case of 1836 and 1400 , elution from the Sepharose-HIgG column resulted in complete recovery of the RF activity, but only $10 \%$ recovery of the anti-DNA activity. Similar losses $(>80 \%)$ of anti-dDNA activity have been reported by Lafer et al. (23) for serum absorptions on a dDNA immunoabsorbent column. In the present study, the $10 \%$ anti-dDNA activity was shown to be specifically bound to the SepharoseHIgG, as the anti-DNA activity eluted from the control Sepharose-BSA column was always $<1 \%$. These immunoabsorption studies demonstrate that both activities were due to a single hybridoma antibody.

The dual reactivities of the hybridoma autoantibodies were further proven by a series of competition experiments. The binding of RF activity to Fc fragments was analyzed after preincubation of the hybridoma antibody with HIgG and dDNA. Those antibodies that showed dual reactivity by direct binding and absorption experiments were competed by both HIgG and dDNA. A hybridoma antibody with only RF activity and lacking anti-DNA activity was competed by HIgG but not by dDNA. These competition experiments support the view that one autoantibody can have dual reactivities. The monoclonality of these antibodies was further substantiated by isoelectric focusing.

The hybridoma autoantibodies described in this study were found to react best with dDNA, of the nuclear antigens tested. Many of these were initially selected for DNA-binding activity, and so might be better described as anti-DNA antibodies with RF activity than as RF with DNA-binding activity. Similar find- ings, in which hybridoma autoantibodies selected for RF activity exhibited higher binding to IDNA and histones, have been reported by Rubin et al. (24) using monoclonal autoantibodies derived from $\mathrm{MRL} / \mathrm{lpr}$ mice. The latter group of investigators have described heterohybridoma (human-mouse) antibodies from patients with RA and SLE that also react with $\mathrm{HIgG}$, dDNA, and histones (25). Preliminary observations using commercial histone preparations demonstrated that 3 of our $17 \mathrm{RF} /$ anti-DNA hybridoma antibodies also bound to isolated histones (data noi shown).

To date, the basis of the dual reactivity of these hybridoma antibodies with both HIgG and nuclear antigens cannot be explained by structural similarities between HIgG and the crossreacting antigens. Although this does not preclude the possibility that HIgG and nuclear antigens share structural epitopes, an alternative explanation may be that these cross-reactive antibodies represent polyfunctional antibodies. The concept of polyfunctional antibodies refers to the multispecificity of antibodies for different antigens that are structurally unrelated (26). In the case of the mouse myeloma protein 460 , which binds the haptens E-DNP-lys and 2-methyl-1,4-naphthoquinone (menadione), Richards et al. (26) determined that the binding sites for these two haptens were nonoverlapping and distinct regions, spatially separated by $\sim 14 \mathrm{~A}$. Autoantibodies reactive with both nuclear antigens and IgG may, similarly, be examples of polyfunctional antibodies.

The results of this study provide support for antigen-binding sites for dDNA and HIgG that are close and possibly overlapping. Although elution of the anti-DNA/RF antibodies from a Sepharose-HIgG column resulted in complete recovery of RF activity, the anti-DNA activity recovered was only $10 \%$. This loss of one reactivity without the other is difficult to explain without postulating two separate binding regions for dDNA and HIgG. It is conceivable that the antibody combining site for dDNA but not for HIgG may have been inactivated by the acid elution procedure.

In the competition experiments, the RF reactivity to $\mathrm{Fc}$ was competed by dDNA and HIgG. However, we were unable to demonstrate competition of the binding of cross-reactive RF/ anti-DNA antibodies to dDNA-coated tubes by HIgG. This may result from the much higher binding avidity of the antibodies for dDNA compared with HIgG, but the possibility of two binding sites must again be considered. The molecular size of the antigen (HIgG or dDNA) may influence the binding of an antibody. DNA is a much larger molecule than $\mathrm{HIgG}$, and may cover the combining site for HIgG when it reacts with its combining site on the RF/anti-DNA antibody. On the other hand, the smaller HIgG molecule, reacting with its combining site on the RF/anti-DNA antibody, may not be large enough to overlap or interfere with the combining site for dDNA.

The elucidation of the molecular basis of cross-reactivities of autoantibodies is essential to the understanding of the potential antigenic reactivities of these antibodies both in vitro and in vivo. The use of hybridoma antibodies provides the potential for designating true cross-reactivities of these autoantibodies and ultimately defining the relevant antigen(s) in these autoimmune diseases.

\section{Acknowledgments}

The authors are indebted to Dr. David Gibson, Sheila MacLean, and Diane Anctil for their expert advice and assistance in the isoelectric focusing analysis; Dr. Jack Karsh for useful discussion regarding the rheu- 
matoid factor assay; and Dorothy McKelvey for excellent secretarial assistance.

This work was supported by research grants from the Arthritis Society of Canada and the Medical Research Council of Canada. Dr. Rauch is a recipient of a Chercheur-Boursier award from the Fonds de la recherche en santé du Québec.

\section{References}

1. Carson, D. A. 1981. Rheumatoid factor. In Textbook of Rheumatology. W. N. Kelley, E. D. Harris, S. Ruddy, and C. B. Sledge, editors. W. B. Saunders Co., Philadelphia. 677-690.

2. Hannestad, K. 1969. M rheumatoid factors reacting with nitrophenyl groups and denatured deoxyribonucleic acid. Ann. NY Acad. Sci. 168:63-75.

3. Hannestad, K., and B. D. Stollar. 1978. Certain rheumatoid factors react with nucleosomes. Nature (Lond.). 275:671-673.

4. Hannestad, K., O. P. Rekvig, and A. Husebekk. 1981. Cross-reacting rheumatoid factors and lupus erythematosus (LE)-factors. Springer Semin. Immunopathol. 4:133-160.

5. Agnello, V., A. Arbetter, G. I. de Kasep, R. Powell, E. M. Tan, and F. Joslin. 1980. Evidence for a subset of rheumatoid factors that cross-react with DNA-histone and have a distinct cross-idiotype. J. Exp. Med. 151:1514-1527.

6. Hobbs, R. N., D. J. Lea, K. K. Phua, and P. M. Johnson. 1983. Binding of isolated rheumatoid factors to histone proteins and basic polycations. Ann. Rheum. Dis. 42:435-438.

7. Tan, E. M., J. Robinson, and P. Robitaille. 1976. Studies on antibodies to histones by immunofluorescence. Scand. J. Immunol. 5:811818.

8. Rubin, R. L., F. G. Joslin, and E. M. Tan. 1982. A solid-phase radioimmunoassay for anti-histone antibodies in human sera: comparison with an immunofluorescence assay. Scand. J. Immunol. 15:63-70.

9. Mason, J. C., P. J. W. Venables, P. R. Smith, and R. N. Maini. 1985. Characterization of non-histone nuclear proteins cross-reactive with purified rheumatoid factors. Ann. Rheum. Dis. 44:287-293.

10. Cunliffe, D. A., and K. O. Cox. 1980. IgM-autoantibodies against isologous erythrocyte also react with isologous $\operatorname{lgG}(\mathrm{Fc})$. Nature (Lond.). 286:720-722.

11. Tan, E. M., A. S. Cohen, J. F. Fries, A. T. Masi, D. J. McShane, N. F. Rothfield, J. G. Schaller, N. Talal, and R. J. Winchester. 1982. The 1982 revised criteria for the classification of systemic lupus erythematosus. Arthritis Rheum. 25:1271-1277.

12. Ropes, M. W., G. A. Bennett, S. Cobb, R. Jacox, and R. A. Jessar. 1958. Revision of diagnostic criteria for rheumatoid arthritis. Bull. Rheum. Dis. 9:175-176.
13. Massicotte, H., J. Rauch, Y. Shoenfeld, and H. Tannenbaum. 1984. Influence of fusion cell ratio and cell plating density on production of human-human hybridomas secreting anti-DNA autoantibodies from patients with systemic lupus erythematosus. Hybridoma. 3(3):215-222.

14. Reif, A. E. 1969. Batch preparation of rabbit \& $G$ globulin with DEAE-cellulose. Immunochemistry. 6:723-731.

15. Greenwood, F. C., W. M. Hunter, and J. S. Glover. 1963. The preparation of ${ }^{131} \mathrm{I}$-labelled human growth hormone of high specific radioactivity. Biochem. J. 89:114-123.

16. Stanworth, D. R., and M. W. Turner. 1973. Immunochemical analysis of immunoglobulins and their subunits. In Handbook of Experimental Immunology. D. M. Weir, editor. Blackwell Scientific Publications, Philadelphia. 10.13.

17. Wernick, R., J. L. Lospalluto, C. W. Fink, and M. Ziff. 1981. Serum IgG and IgM rheumatoid factors by solid phase radioimmunoassay. A comparison between adult and juvenile rheumatoid arthritis. Arthritis Rheum. 24:1501-1511.

18. Hannestad, K., and A. Johannessen. 1976. Polyclonal human antibodies to IgG (rheumatoid factors) which cross-react with cell nuclei. Scand. J. Immunol. 5:541-547.

19. Rauch, J., M. Tannenbaum, H. Tannenbaum, P. R. Cullis, C. P. S. Tilcock, M. S. Hope, and A. S. Janoff. 1985. Human hybridoma lupus anticoagulant recognize hexagonal but not lamellar phospholipids. Fed. Proc. 44:601. (Abstr.)

20. Gibson, D. 1976. Genetic polymorphism of mouse immunoglobulin light chains revealed by isoelectric focusing. J. Exp. Med. 144: 298-303.

21. Gibson, D. M., B. A. Taylor, and M. Cherry. 1978. Evidence for close linkage of a mouse light chain marker with the Ly-2,3 locus. $J$. Immunol. 121:1585-1590.

22. Awdeh, Z. I., A. R. Williamson, and B. A. Askonas. 1970. One cell-one immunoglobulin. Origin of limited heterogeneity of myeloma proteins. Biochem. J. 116:241-248.

23. Lafer, E. M., R. P. C. Valle, A. Moller, A. Nordheim, P. H. Schur, A. Rich, and B. D. Stollar. 1983. Z-DNA-specific antibodies in human systemic lupus erythematosus. J. Clin. Invest. 7:314-321.

24. Rubin, R. L., R. S. Balderas, E. M. Tan, F. J. Dixon, and A. N. Theofilopoulos. 1984. Multiple autoantigen binding capabilities of mouse monoclonal antibodies selected for rheumatoid factor activity. J. Exp. Med. 159:1429-1440.

25. Theofilopoulos, A. N., R. Rubin, R. Balderas, G. Tsokos, E. Tan, and F. J. Dixon. 1984. Monoclonal mouse and human rheumatoid factors with multiple autoantigen specificities. Fed. Proc. 43:1735. (Abstr.)

26. Richards, F. F., W. H. Konigsberg, R. W. Rosenstein, and J. M. Varga. 1975. On the specificity of antibodies. Biochemical and biophysical evidence indicates the existence of polyfunctional antibody combining regions. Science (Wash. DC). 187:130-136. 